\title{
Candidate genes for the development of hair follicles in Hu sheep
}

\author{
X.Y. Lv ${ }^{1}$, R. Ni ${ }^{1}$, W. Sun ${ }^{1}$, R. Su${ }^{1}$, H.H. Musa ${ }^{2}$, J.F. Yin ${ }^{1}$, Q.Z. Wang ${ }^{1}$, \\ W. Gao ${ }^{1}$ and L. Chen ${ }^{3}$ \\ ${ }^{1}$ College of Animal Science and Technology, Yangzhou University Yangzhou, \\ China \\ ${ }^{2}$ Faculty of Medical Laboratory Sciences, University of Khartoum Khartoum, \\ Sudan \\ ${ }^{3}$ Animal Science and Veterinary Medicine Bureau of Suzhou City Suzhou, \\ China \\ Corresponding author: W. Sun \\ E-mail: dkxmsunwei@163.com
}

Genet. Mol. Res. 15 (3): gmr.15036877

Received May 28, 2015

Accepted August 12, 2015

Published August 5, 2016

DOI http://dx.doi.org/10.4238/gmr.15036877

Copyright (C) 2016 The Authors. This is an open-access article distributed under the terms of the Creative Commons Attribution ShareAlike (CC BY-SA) 4.0 License

ABSTRACT. The aim of this study was to detect candidate genes for the development of hair follicles in the Hu sheep breed. Seven genes have been detected in large, medium, and small wave follicles of Hu sheep using gene chip technology. The histological features of the follicles of newborn Hu-lambs were combined with fluorescence quantitative PCR technology to detect the correlation between the expression of the seven genes and hair follicle development. Among the genes studied, matrix metalloproteinase $2(M M P 2)$, bone morphogenetic protein-7 (BMP7), and sideroflexin 1 (SFXN1) showed a significantly different pattern of expression in large, medium, and small wave follicles $(\mathrm{P}<$ 0.05). The expression of $M M P 2$ had a significant positive correlation with secondary follicles in large waves $(\mathrm{P}<0.05)$, while the expression 
of $B M P 7$ had a significant correlation with primary follicle diameter in small wave follicles, and a highly significant positive correlation with the number of secondary follicles in the small waves $(\mathrm{P}<0.01)$. The expression of $S F X N 1$ was significantly and positively correlated with the diameters of small wave primary follicles; it also showed a highly significant positive correlation with secondary follicle diameters. Although other genes are associated with hair follicles, their expression in large, medium, and small wave follicles was not significant. We propose that $B M P 7, M M P 2$, and $S F X N 1$ genes could be important candidate genes for use in breeding $\mathrm{Hu}$ lambs with early coat development.

Key words: Hu sheep; Hair follicle; Patterns

\section{INTRODUCTION}

The Hu sheep breed is particularly noted for the characteristics of the lambskin obtained from lambs slaughtered within 3 days of birth. The skins from these lambs have soft white hair with a wavy pattern; the wavy patterns gradually disappear at 3 days after birth and the quality of lambskin diminishes. There are great differences in the lambskin qualities in $\mathrm{Hu}$ sheep: the pattern of the hair follicles varies, with three types of waves, large, medium, and small. The average width of the small wave is $0.5-1.25 \mathrm{~cm}$, the medium wave is $1.25-2.0 \mathrm{~cm}$, and the large wave is more than $2.0 \mathrm{~cm}$. In terms of quality, the small waves are better than medium and large waves. Additionally, different lambs from the same ewe may show different patterns of wool curl and patterns. However, genetic factors are known to play an important role in the patterns of hair follicle formation in lambskin. The hair follicles on lambskin can be divided into myelinated wool primary follicles and non-myelinated wool secondary follicles. Identification of genes associated with hair follicle development will provide greater insights into the generation of the different patterns in Hu lambskin. Here, we studied individuals with three distinctively different patterns as the material for comparison.

A previous study of differentially expressed genes in Hu lambskin based on microarray technology and bioinformatic analysis identified BMP7, MMP2, CDKNIC, MT3, SFXN1, $S N A I$, and IL13RAI as candidate genes involved in the formation of different wool patterns (Sun et al., 2013). Bone morphogenetic protein-7 (BMP7) is a member of the transforming growth factor- $\beta$ (TGF- $\beta$ ) superfamily. In vivo and in vitro experiments have confirmed that TGF- $\beta$ can stimulate hair follicle epithelial cells (Oshimori and Fuchs, 2012). Noramly and Morgan (1998) reported that $B M P 1$ and $B M P 7$ expression are related to the size of the feather germ and its spatial distribution. These observations suggest that this protein family may play a potential role in the development of hair follicles. $B M P 2, B M P 4$, and $B M P 7$ have been found to be expressed in developing hair follicles (Thomadakis et al., 1999). Genetic studies confirmed that BMP signaling plays an important role in the control of cell differentiation and apoptosis (Botchkarev and Sharov, 2004). Recent studies on hair follicles concentrated mainly on the roles of $B M P 2$ and $B M P 4$; the function of $B M P 7$ in cancer has been examined (Qian et al., 2009) and the whole sequence has been cloned (Zhao et al., 2009). Matrix metalloproteinase $2(M M P 2)$ is involved in physiological processes including cell proliferation, differentiation,

Genetics and Molecular Research 15 (3): gmr.15036877 
bone formation, and collagen catabolism, and is a negative regulator of cell adhesion. It can shear and process insulin-like growth factor and then trigger activity of insulin-like growth factor $(I G F)$. It plays an important role in cell proliferation, differentiation, and inhibition of apoptosis (Sternlicht and Werb, 2001). CDKNIC, MT3, SFXN1, SNAI, and IL13RA1 genes are all involved in cell proliferation, differentiation and apoptosis (Sun et al., 2013). MT3 is also involved in esophageal cancer (Tian et al., 2004), CDKNIC in colorectal cancer (Zeng et al., 2011), and SNA1 in breast cancer (Yu, 2010); whether these genes are also related to the growth and development of hair follicles is not yet clear.

Although some research has examined the growth cycle of hair follicles of goats (Sun et al., 1984; Li et al., 2005), there is no detailed information on gene expression during hair follicle development in skin tissue of newborn $\mathrm{Hu}$ sheep. Here, we investigated expression changes in BMP7, MMP2, CDKNIC, MT3, SFXN11, SNAI, and IL13RA1 in newborn Hu lambs and examined the relationship between expression of these genes and large, medium, and small waves follicles during hair development These analyses are expected to elucidate the role of these genes on hair follicle development and to provide a basis for improvement in breeding high quality lambs.

\section{MATERIAL AND METHODS}

The research was carried out in Suzhou stud farm and Yangzhou University, Jiangsu Province Key Laboratory-Animal Genetic and Molecular Design Laboratory.

\section{Experimental populations}

Fifteen 2-day-old Hu lambs were selected from Suzhou stud farm in Jiangsu Province: 6 groups of full-sib individuals, in which 3 groups showed small and large waves, whereas the other groups showed large, medium, and small waves. The waves were measured on the skin of the back. An approximately $1.5 \mathrm{~cm}^{2}$ skin was cut off and then cut into small pieces and placed into an RNA-free tubes and stored with RNA preservation solution in a $4{ }^{\circ} \mathrm{C}$ refrigerator overnight, and then stored at $-70^{\circ} \mathrm{C}$. Another piece of skin was attached to cardboard and fixed in $4 \%$ formaldehyde.

\section{Reagents and instruments}

The PrimeScript RT reagent kit and the SYBR Premix Ex Taq ${ }^{\mathrm{TM}}$ II kit were purchased from Takara Biotechnology Co. Ltd. (Dalian); RNA preservation solution was purchased from Tiangen Biochemical Science and Technology Co. Ltd. (Beijing, China). The ABI 7500 Real-Time PCR instrument was purchased from the Applied Biosystems. Formaldehyde, alcohol, paraffin, and iodine were purchased from Sangon Biological Engineering Co. Ltd (Shanghai, China).

\section{Paraffin sections}

Skin biopsies of large, medium, and small waves were used to prepare conventional paraffin sections. After fixation, the tissues were dehydrated, cleared, embedded, sectioned, and hematoxylin and eosin stained by standard means. Hair follicle structure was observed

Genetics and Molecular Research 15 (3): gmr.15036877 
under the optical microscope, and images were captured with a scanning microscopic imaging system. Each slice selected three different horizons. The numbers of primary and secondary hair follicles and their diameters were determined. SPSS17.0 software was used for univariate analysis of variance (ANOVA) of the data. Significance was set at $\mathrm{P}<0.05$.

\section{Real-time PCR}

RNA was extracted from pieces of Hu lamb skin using conventional methods (Sun et al., 2013). cDNA was prepared using a PrimeSYBR RT Reagent Kit and Perfect Real Time kit (TaKaRa). The reaction mixture contained $2 \mu \mathrm{L}, 5 \mathrm{X}$ PrimeScript Buffer, $0.5 \mu \mathrm{L}$ PrimeScript RT Enzyme Mix I, $0.5 \mu \mathrm{L}$ oligo dT primer, $0.5 \mu \mathrm{L}$ random 6 mers, $4 \mu \mathrm{L}$ total RNA, and $2.5 \mu \mathrm{L}$ RNase free $\mathrm{dH}_{2} 0$. Amplification conditions were $37^{\circ} \mathrm{C}$ for $15 \mathrm{~min}, 85^{\circ} \mathrm{C}$ for $5 \mathrm{~s}$. The primers were designed using the Oligo 7 software and are described in Table 1. To synthesize the first strand of cDNA, a standard PCR amplification was used. GAPDH was used as the reference gene and the SYBR Green I method was used for quantitative testing. A standard curve was established using cDNA gradient dilution, and each sample was tested 3 times in the 7500 PCR instrument for RT-PCR. The relative expression of the target gene was calculated according to the $2^{-\Delta \Delta \mathrm{Ct}}$ method.

\begin{tabular}{|c|c|c|}
\hline Gene name & Primer sequences $\left(5^{\prime} \rightarrow 3^{\prime}\right)$ & Fragment size (bp) \\
\hline GAPDH & $\begin{array}{l}\text { F: GTTCCACGGCACAGTCAAGG } \\
\text { R: ACTCAGCACCAGCATCACCC }\end{array}$ & 127 \\
\hline BMP7 & $\begin{array}{l}\text { F: TGAGTTCCGCATTTACAAGG } \\
\text { R: GTGGCTGTGATGTCAAAAAC }\end{array}$ & 177 \\
\hline MMP2 & $\begin{array}{l}\text { F: GTACCCCAAGCCGCTGACC } \\
\text { R: TCCAGAATTTGTCTCCAGCGAAG }\end{array}$ & 116 \\
\hline MT3 & $\begin{array}{l}\text { F: CTCCTGCACCTGCTCCGACTC } \\
\text { R: TCCAGAATTTGTCTCCAGCGAAG }\end{array}$ & 99 \\
\hline CDKNIC & $\begin{array}{l}\text { F: GGCACCTCACTCGCATCTG } \\
\text { R: AAGCGCGAAGAGACTGCAAG }\end{array}$ & 127 \\
\hline SFXN1 & $\begin{array}{l}\text { F: CAAACAAGCCATCACGCAAG } \\
\text { R: GCAAAAGCCAACTATTCCAAC }\end{array}$ & 160 \\
\hline IL13RA1 & $\begin{array}{l}\text { F: GTGGAAAAGTGCATCTCGC } \\
\text { R: TACTTGGACGCTGTGCTGTT }\end{array}$ & 273 \\
\hline SNAII & $\begin{array}{l}\text { F: GCCCGCCGGAGACCCAATTA } \\
\text { R: GAGCCAAGAGAGTCCCAGATGAG }\end{array}$ & 161 \\
\hline
\end{tabular}

\section{RESULTS}

\section{Total RNA quality test}

The concentration of RNA was measured using a Nano Drop ND-1000 Spectrophotometer (Nano Drop Technologies, Wilmington, USA) and samples with a purity $\left(\mathrm{A}_{260} / \mathrm{A}_{280}\right)$ of $>1.8$ were used. Clear bands at $18 \mathrm{~S}$ and $28 \mathrm{~S}$ were detected on a gel (Figure 1).

\section{Augmented product}

The dissolution curves showed relatively sharp single peaks for the seven target genes and $G A P D H$, indicating the high quality of the designed primers and the optimization of the PCR (Figure 2). 


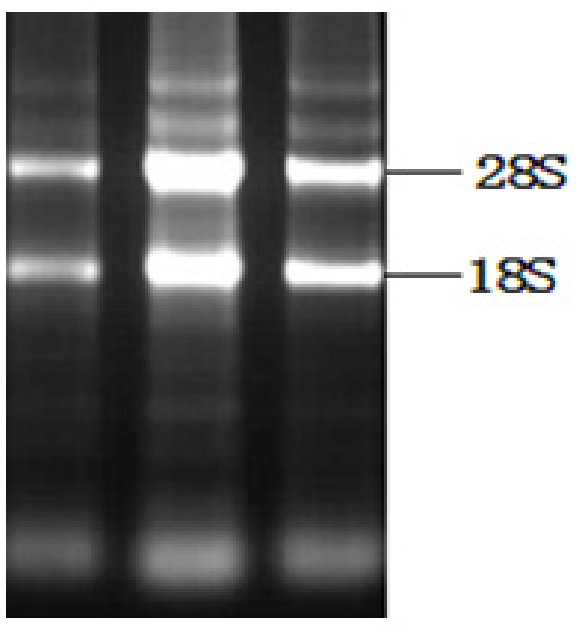

Figure 1. Total RNA from 2-day-old Hu lambskin.
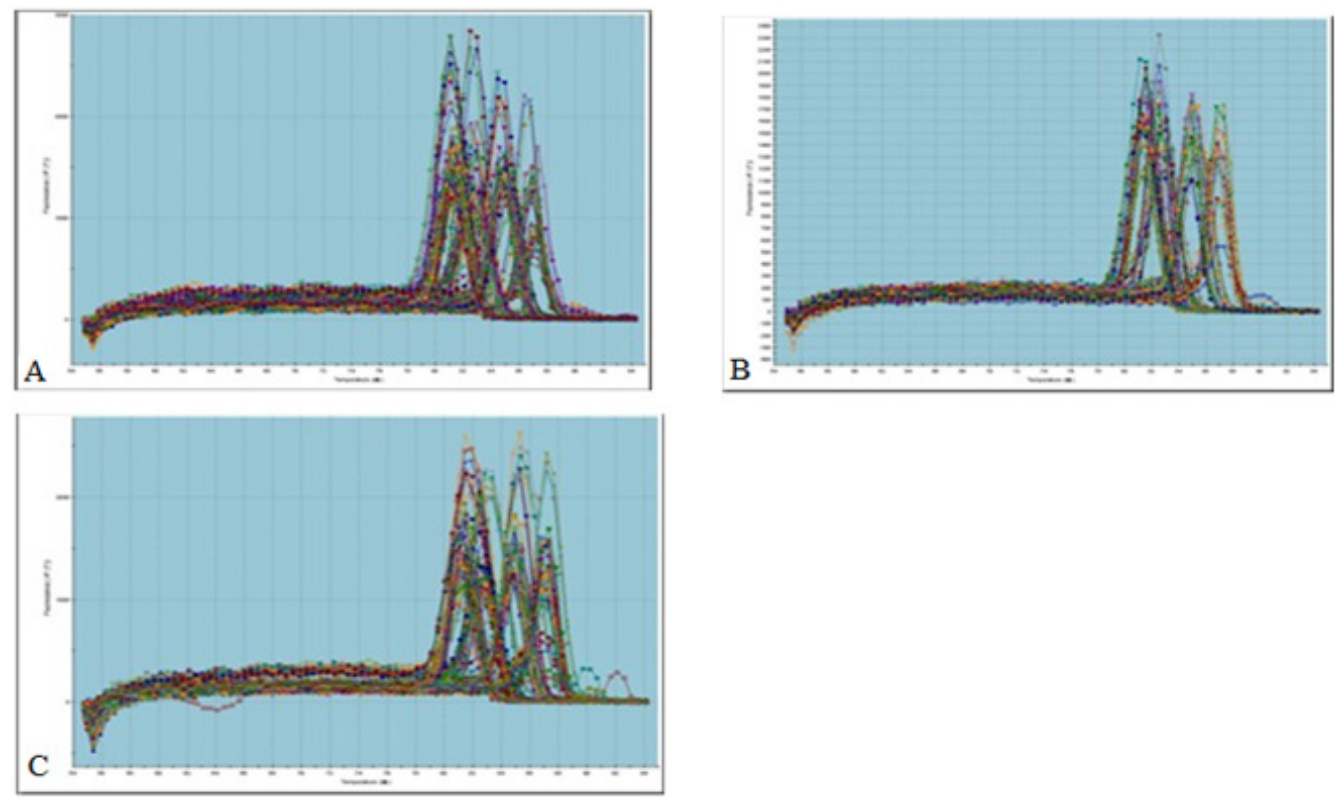

Figure 2. Dissolution curves for $G A P D H$ and the seven tested genes.

\section{Structural characteristics of hair follicles in Hu sheep}

Transverse section images of large, medium, and small waves are shown in Figure 3.

Genetics and Molecular Research 15 (3): gmr.15036877 


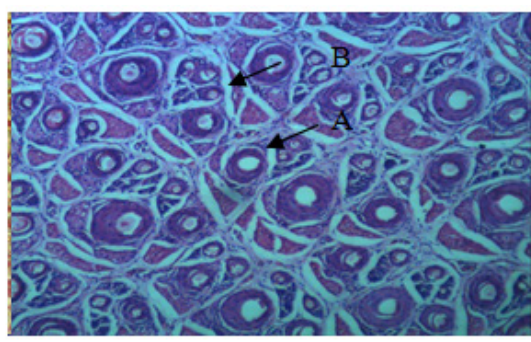

Large waves $(100 \times)$

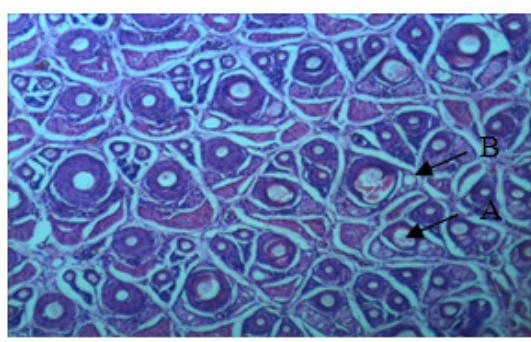

Small waves $(100 \times)$

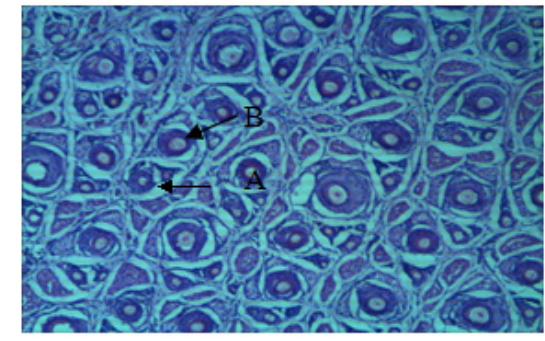

Medium waves (100x)

Figure 3. Transverse section images of large, medium, and small wave follicles.

The diameters of primary and secondary follicles and the number of primary and secondary follicles are given in Table 2 .

Table 2. Characteristics of large, medium, and small wave follicles.

\begin{tabular}{l|c|c|c|c|c}
\hline Group & No. of individuals & No. of primary follicles & No. of secondary follicles & Diameter of primary follicles $(\mu \mathrm{m})$ & Diameter of secondary follicles $(\mu \mathrm{m})$ \\
\hline Large waves & 6 & $38.33 \pm 2.13^{\mathrm{a}}$ & $18.44 \pm 0.84^{\mathrm{A}}$ & $80.02 \pm 1.42^{\mathrm{A}}$ & $44.73 \pm 0.69^{\mathrm{A}}$ \\
\hline Medium waves & 3 & $37.22 \pm 1.50^{\mathrm{A}}$ & $13.56 \pm 0.53^{\mathrm{B}}$ & $72.41 \pm 2.32^{\mathrm{B}}$ & $35.91 \pm 1.22^{\mathrm{B}}$ \\
\hline Small waves & 6 & $37.67 \pm 0.75^{\mathrm{a}}$ & $17.39 \pm 0.57^{\mathrm{A}}$ & $73.95 \pm 0.80^{\mathrm{B}}$ & $43.38 \pm 1.26^{\mathrm{A}}$ \\
\hline
\end{tabular}

Means with different lower-case letters within the same column indicate significant differences between different rows. Means with different capital superscripts within the same column indicate highly significant differences between different rows. Means with the same lowercase letter within the same column indicate no significant differences between different rows.

The diameters of primary follicles were significantly larger in large waves compared to medium and small waves $(\mathrm{P}<0.01)$; there were no significant differences in size between primary follicles of medium and small waves $(\mathrm{P}>0.05)$. The diameter of secondary follicles in medium waves was significantly smaller than in large and small waves $(\mathrm{P}<0.01)$; there was no significant difference in size between large and small waves $(\mathrm{P}>0.05)$. The number of primary follicles among large, medium, and small waves did not differ significantly $(\mathrm{P}>$ $0.05)$; however, the number of primary follicles in large waves was higher than in the medium and small waves. The number of secondary follicles in medium waves was significantly lower than in large and small waves $(\mathrm{P}<0.01)$; large and small waves did not differ significantly $(\mathrm{P}>$ 0.05 ) (Table 2). Most hair follicle groups in three different patterns consisted of 3 follicles, the 
central primary follicle had the largest diameter, and the side primary follicles were somewhat smaller (Figure 3).

\section{Gene expression in large, medium, and small waves}

cDNAs from large, medium, and small waves were prepared as described above. The level of expression of $B M P 7$ and $S F X N 1$ was significantly higher in medium and large waves compared to small waves $(\mathrm{P}<0.05)$. The level of expression of $M M P 2$ was significantly higher in medium waves than small and large waves $(\mathrm{P}<0.01)$. None of the other tested genes showed any significant differences in expression among large, medium, and small waves (Table 3).

Table 3. Relative expression of 7 genes among 3 groups.

\begin{tabular}{l|c|c|c}
\hline Genes name & Relative expression of large waves & Relative expression of medium waves & Relative expression of small waves \\
\hline BMP7 & $1.18 \pm 0.07^{\mathrm{a}}$ & $1.19 \pm 0.14^{\mathrm{a}}$ & $1^{\mathrm{b}}$ \\
\hline MMP2 & $0.99 \pm 0.81^{\mathrm{B}}$ & $1.71 \pm 0.24^{\mathrm{A}}$ & $1^{\mathrm{B}}$ \\
\hline CDKNIC & $0.97 \pm 0.11^{\mathrm{a}}$ & $0.93 \pm 0.089^{\mathrm{a}}$ & $1^{\mathrm{a}}$ \\
\hline MT3 & $0.99 \pm 0.11^{\mathrm{a}}$ & $0.93 \pm 0.089^{\mathrm{a}}$ & $1^{\mathrm{a}}$ \\
\hline SFXN1 & $1.21 \pm 0.08^{\mathrm{a}}$ & $1.35 \pm 0.13^{\mathrm{a}}$ & $1^{\mathrm{a}}$ \\
\hline SNAI & $1.07 \pm 0.08^{\mathrm{a}}$ & $1.17 \pm 0.14^{\mathrm{a}}$ & $1^{\mathrm{a}}$ \\
\hline IL13RA1 & $1.17 \pm 0.11^{\mathrm{a}}$ & $1.34 \pm 0.18^{\mathrm{a}}$ & \\
\hline
\end{tabular}

Means with different lower-case letters within the same column indicate significant differences between different rows. Means with different capital superscripts within the same column indicate extremely significant differences between different rows. Means with the same lower-case letter within the same column indicate no significant differences between different rows. The diameters of large wave secondary follicles.

\section{Correlation between expression of tested genes and follicle characteristics}

The diameters and numbers of primary and secondary follicles are crucial to the formation of the wave patterns. We examined the correlation between the level of expression of the seven tested genes and hair follicle characteristics in large, medium, and small wave groups. All seven genes showed significant correlations with some of the hair follicle characteristics, suggesting that all of them may be involved in hair follicle development (Table 4).

Table 4. Correlation between the expressed genes and the follicle characteristics.

\begin{tabular}{l|c|c|c|c|c|c|c}
\hline Index & BMP7 & CDKNIC & MT-3 & MMP2 & IL13R1 & SFXN1 & SNA1 \\
\hline Diameters of large waves primary follicles & 0.037 & 0.230 & 0.409 & -0.113 & -0.104 & $-0.496^{*}$ & -0.195 \\
\hline Diameters of large waves secondary follicles & 0.389 & $0.593^{* *}$ & $0.516^{* *}$ & 0.383 & 0.311 & 0.358 & 0.244 \\
\hline Diameters of small waves primary follicles & $0.501^{*}$ & 0.323 & 0.055 & 0.340 & $0.499^{*}$ & $0.507^{*}$ & $0.573^{*}$ \\
\hline Diameters of small waves secondary follicles & 0.174 & -0.424 & 0.205 & 0.102 & 0.102 & $0.623^{* *}$ & 0.147 \\
\hline Diameters of medium waves primary follicles & $-0.667^{*}$ & -0.603 & 0.119 & -0.375 & $-0.737^{*}$ & $-0.801^{* *}$ & $-0.737^{*}$ \\
\hline Diameters of medium waves secondary follicles & -0.515 & -0.205 & 0.183 & -0.109 & -0.424 & -0.285 & -0.566 \\
\hline Number of large waves primary follicles & -0.157 & $-0.475^{* *}$ & $-0.681^{* *}$ & 0.198 & -0.085 & 0.325 & 0.321 \\
\hline Number of large waves secondary follicles & 0.319 & 0.180 & 0.033 & $0.500^{*}$ & 0.431 & 0.449 & $0.567^{*}$ \\
\hline Number of small waves primary follicles & -0.395 & $-0.602^{* *}$ & $-0.768^{* *}$ & -0.293 & -0.202 & -0.372 & -0.029 \\
\hline Number of small waves secondary follicles & $0.650^{* *}$ & 0.250 & 0.274 & 0.431 & $0.541^{*}$ & 0.327 & $0.493^{*}$ \\
\hline Number of medium waves primary follicles & 0.410 & 0.364 & -0.066 & 0.390 & 0.447 & $0.680^{*}$ & 0.609 \\
\hline Number of medium waves secondary follicles & $-0.771^{*}$ & -0.264 & 0.487 & -0.039 & $-0.670^{*}$ & -0.410 & -0.643 \\
\hline
\end{tabular}

Genetics and Molecular Research 15 (3): gmr.15036877 


\section{DISCUSSION}

As a constituent of the skin, the hair follicle is the tissue regulator that directly controls hair growth, development, differentiation, and cyclical adjustment. Wool has two types of fiber, marrowless velvet and medulla developed hair; myelinated hair occurs in primary follicles, and growing un-myelinated hair occurs in secondary follicles (Li et al., 2005). Secondary follicles differentiate from primary hair follicles. Primary follicles have a complete set of associated structures, such as a large hair ball deep in the dermis, and are surrounded by sebaceous glands, sweat glands, arrectores pilorum, and other ancillary structures. However, in secondary follicles, the hair ball is located at a shallow position in the dermis; secondary follicles have small diameters, no sweat gland, or erector muscle, and only a small number of sebaceous glands located in a further shallow position ( $\mathrm{Du}, 1982$ ). In the present study, we showed that the primary and secondary follicles in skin of 2-day-old Hu lambs were fully developed, and that most waves consisted of 3 follicles. The centrally located primary follicle had the largest diameter, while the lateral primary follicles had smaller diameters; these were surrounded by 1 or 2 secondary follicles. The density of the primary and secondary follicles determines the fineness and pattern of the wool (Lin et al., 2000; Botchkarev et al., 2002; Purvis and Swan, 2002): the larger the diameter of the hair follicles, then the more rough and poor texture of the wool. Our analyses showed that the diameter of the large-wave hair follicles was greater than those of the medium and small waves. The diameters of the primary and secondary small-wave follicles were intermediate between large and small waves. The wool quality of small waves is considered far superior to that of large and medium waves, which are merely acceptable materials for preparation of wool products.

The transforming growth factor- $\beta(T G F-\beta)$ superfamily member, $B M P 7$, is expressed in hair follicle development. There is evidence that $B M P 2, B M P 4$, and $B M P$ receptor $I A$ are expressed in epidermal cells that synthesize keratin in the hair bulb (Wozney et al., 1988). Moreover, the expression of $B M P 2$ in telogen was approximately 25 -fold higher than in the proliferation phase of development of hair follicles of Inner Mongolia Cashmere goats ( $\mathrm{Su}$ et al., 2008). On the other hand, $B M P 4$ showed a lower level of expression in telogen and a much elevated level in the proliferation phase of secondary hair follicles, suggesting that $B M P 2$ and $B M P 4$ had an inhibiting effect on hair follicle development (Wu et al., 2009). In the present study, we showed that the expression of $B M P 7$ in small wave follicles was significantly higher than large wave follicles during the same period, suggesting that $B M P 7$ might be involved in the development of hair follicles and the regulation of hair growth. The MMP2 and SFXN1 genes varied in expression among large, medium, and small wave follicles. We speculate that these genes might have a role in the development of hair follicles, but their exact function will need to be clarified in future studies.

The pattern of expression of BMP7 was consistent with the follicle number and diameter characteristics of primary and secondary hair follicles. In combination with the results of the differences in expression of $B M P 7$ in large, medium, and small waves, we suggest that $B M P 7$ may have a role in the regulation of hair follicle development. The pattern of $M M P 2$ expression showed that the number of hair follicles had significant difference in small wave large and medium waves, and was consistent with the biopsy results. Similarly, $S F X N 1$ expression showed that the diameter of hair follicle had significant difference in small wave large and medium waves. Although $S F X N 1$ expression was inconsistent with the biopsy

Genetics and Molecular Research 15 (3): gmr.15036877 
results. This may have been due to insufficient sample size since the tissues were obtained from full-sib lambs, we suggest that $M M P 2$ and $S F X N 1$ may also have a role in the regulation of hair follicle development Finally, we conclude that the BMP7, MMP2 and SFXN1 genes, which were expressed in large, medium and small waves, were candidates genes for hair follicle development.

\section{Conflicts of interest}

The authors declare no conflict of interest.

\section{ACKNOWLEDGMENTS}

Research supported by the Projects of Domesticated Animals Platform of the Ministry of Science and Technology of China, Jiangsu Agricultural Science and Technology Support Program of China (\#BE2012331), the Graduate Education Innovation Project of Jiangsu Province of China (\#CXLX15-1375, KYLX_1356), the Project Funded by the Priority Academic Program Development of Jiangsu Higher Education Institutions, the Project of Jiangsu Province Engineering Research Center of China (\#BM2012308), the Key Project of the National Spark Program of China (\#2012GA690003), the Subei Science and Technology Program of Jiangsu Province of China (\#BN2014003), the Project of Jiangsu Province Agricultural Science and Technology Innovation Fund [\#CX(14)2073], and the Project of Six Peak of Talents of Jiangsu Province of China.

\section{REFERENCES}

Botchkarev VA and Sharov AA (2004). BMP signaling in the control of skin development and hair follicle growth. Differentiation 72: 512-526. http://dx.doi.org/10.1111/j.1432-0436.2004.07209005.x

Botchkarev VA, Botchkareva NV, Sharov AA, Funa K, et al. (2002). Modulation of BMP signaling by noggin is required for induction of the secondary (nontylotrich) hair follicles. J. Invest. Dermatol. 118: 3-10. http://dx.doi.org/10.1046/ j.1523-1747.2002.01645.x

Du JZ (1982). The factors influences the quality of lamb skin and improving method. Agric. Sci. Tech. Commun. (10): 37.

Li CQ, Yin J, Zhang YJ, Guo ZC, Zhang WG, et al. (2005). Comparative study on skin and hair follicles cycling between inner Mongolia and Liaoning cashmere goats. Acta Veterinaria et Zootechnica Sinica 36: 674-679.

Lin MH, Leimeister C, Gessler M and Kopan R (2000). Activation of the Notch pathway in the hair cortex leads to aberrant differentiation of the adjacent hair-shaft layers. Development 127: 2421-2432.

Noramly S and Morgan BA (1998). BMPs mediate lateral inhibition at successive stages in feather tract development. Development 125: 3775-3787.

Oshimori N and Fuchs E (2012). Paracrine TGF- $\beta$ signaling counterbalances BMP-mediated repression in hair follicle stem cell activation. Cell Stem Cell 10: 63-75. http://dx.doi.org/10.1016/j.stem.2011.11.005

Purvis IW and Swan AA (2002). Breeding for wool quality in apparel wool sheep. Proceedings of the 7th World Congress on Genetics Applied to Livestock Production, Montpelier.

Qian H, Xie Y, Peng XJ, Gu HB, et al. (2009). The significance of quantitative detection of BMP7 gene expression in diagnosis of colorectal and gastric cancers. Northwest Sci-Tech University of Agriculture and Forestry 27: 434-436.

Sternlicht MD and Werb Z (2001). How matrix metalloproteinases regulate cell behavior. Annu. Rev. Cell Dev. Biol. 17: 463-516. http://dx.doi.org/10.1146/annurev.cellbio.17.1.463

Su R, Li JQ, Zhang WG, Yin J, et al. (2008). Expression of BMP2 in the skin and hair follicle from different stage in inner Mongolia Cashmere Goat. Scientia Agriculture Sinica 41: 559-563.

Sun HZ, Hou XZ and Hong M (1984). Research on the development of Inner Mongolia Arbas Cashmere goat hair follicles and activity changes. Inner Mongolia Animal Husbandry Science 4: 3-6.

Sun W, Ni R, Yin JF, Musa HH, et al. (2013). Genome array of hair follicle genes in lambskin with different patterns. PLoS

Genetics and Molecular Research 15 (3): gmr.15036877 
One 8: e68840. http://dx.doi.org/10.1371/journal.pone.0068840

Thomadakis G, Ramoshebi LN, Crooks J, Rueger DC, et al. (1999). Immunolocalization of Bone Morphogenetic Protein-2 and -3 and Osteogenic Protein-1 during murine tooth root morphogenesis and in other craniofacial structures. Eur. $J$. Oral Sci. 107: 368-377. http://dx.doi.org/10.1046/j.0909-8836.1999.eos107508.x

Tian ZQ, Liu JF, Zhang YF, Li Y, et al. (2004). Clinical significance of CpG island methylation of MT-3 gene in squamous cell carcinoma of esophagus. J. Pract. Oncol. 19: 386-389.

Wozney JM, Rosen V, Celeste AJ, Mitsock LM, et al. (1988). Novel regulators of bone formation: molecular clones and activities. Science 242: 1528-1534. http://dx.doi.org/10.1126/science.3201241

Wu JH, Zhang WG, Li JQ, Yan ZW (2009). BMP4 expression in different periods of hair follicles development of Inner Monglia Cashmere goat. Heilongjiang Animal Science and Veterinary Medicine 12: 35-36.

Yu LN (2010). The effect of shRNA mediated gene silencing of transcription factor SNAI1 on biological phenotypes in breast cancer cell line MCF-7. Jilin University, Changchun.

Zeng JJ, Sun K, Wu CT, Lei ST, et al. (2011). Differential expression of microRNA-221 and CDKNIC/P57 in colorectal carcinoma and adjacent non-tumorous tissues. Chin. J. Exp. Surg. 28: 19-20.

Zhao QH, Chen QX, Li M, Shi XW, et al. (2009). Cloning and sequence analysis of the 3'UTR of rabbit BMP7. Journal of Northwest A\&F University 37(2): 11-14.

Genetics and Molecular Research 15 (3): gmr.15036877 